\title{
Informing learning design in online education using learning analytics of student engagement
}

\author{
Quan Nguyen, Bart Rienties and Denise Whitelock
}

\section{I4.I Introduction}

Since the early 2000s, two strands of research in education have emerged that can help educators gain better insights into the teaching and learning process. These are learning design (LD) and learning analytics (LA). Learning design, in this context, is defined as "a descriptive framework for teaching and learning activities ("educational notation"), and to explore how this framework can assist educators to share and adopt great teaching ideas." (Dalziel et al., 2016, p. 4). Research in LD has developed a wide range of tools and frameworks to document and visualise sequences of learning activities designed by teachers and to guide them through the LD process (Cross et al., 2012; Laurillard et al., 2018). Through the transition from implicit to explicit representations of LD, teachers can reflect on their practices, while re-using and adapting good instructional approaches from others (Agostinho et al., 2011).

In parallel to LD, LA has emerged as a field in the decade since the first Learning Analytics Knowledge (LAK) conference in 2011. Learning analytics is defined as "the measurement, collection, analysis and reporting of data about students and their contexts, for purposes of understanding and optimising learning and the environments in which it occurs" (Ferguson, 2012, p. 305). LA research typically collects a large amount of data about students such as demographics, course performance, activity logs of students (Rienties et al., 2019; Tempelaar et al., 2018), discussion forums interactions (Wise et al., 2017), and open texts from essays or course evaluations (Ullmann, 2019). By taking advantage of advanced analytical techniques such as machine learning (Ullmann, 2019), text-mining (Hillaire et al., 2022), and social network analysis (Wise et al., 2017), LA has created practical applications to support the learning process.

There exists a strong synergy between the two fields (Lockyer \& Dawson, 2011). On the one hand, LA provides data and tools to test pedagogical assumptions in LD against actual student interactions. On the other hand, LD provides the necessary contextual overlay to better understand observed student behaviour and translate LA findings into actionable insights (Lockyer \& Dawson, 2011). Prior empirical works have shown the benefits of embedding LD in LA such as improving predictive accuracy of academic performance (Gašević et al., 2016), understanding the 
impact of LD on student engagement, satisfaction, and performance (Rienties \& Toetenel, 2016), exploring the variety of designing approaches (Nguyen et al., 2017a, 2017b, 2017), uncovering the (in)consistency between students' engagement and instructors' learning design (Nguyen et al., 2018a, 2018b, 2018), and highlighting in Chapter 8 that geocultural background characteristics of learners influence engagement with LD (Rizvi et al., 2022). The next sections will outline some applications of learning analytics to inform learning design in online education, using large-scale empirical findings from over three years of extensive research at the Open University UK (OU).

\subsection{Background}

\subsection{Study context}

All the studies reported in this chapter took place at the OU.The OU is the largest academic institution in the UK and in Europe with over 170,000 enrolled students. As a pioneer in distance learning model since 1969, the OU offers more than 200 qualifications and 400 modules via a distance learning model, which involves the use of a Virtual Learning Environment (VLE) in conjunction with online and/or face-to-face tutorials with designated tutors. The OU is a leading research institution in learning analytics (Clow, 2013; Ferguson, 2012; Herodotou et al., 2019). For example, OU Analyse produces an early prediction of "at-risk" students based on their demographic data and their interaction with the VLE (Kuzilek et al., 2015). In addition, the OU has a rich database of its students including demographics, academic performance, course registration, and trace data of activities on VLE across hundreds of thousands of students since 1970s. Therefore, the OU provides a unique opportunity for LA researchers to address educational research questions at a large-scale, improving the external validity and generalisability of the findings.

\subsubsection{Learning design at the Open University}

Compared to other universities, the OU module production process is longer and more complex. This process typically takes two to four years, involving multiple stakeholders with specialised skills in academic content writing, teaching, project management, media production and technical development (Cross et al., 2012). Capturing and quantifying pedagogical practices is challenging, to say the least. At the OU, each new module goes through a mapping process, which maps out all learning activities and their estimated time to complete the activities. Learning activities are categorised based on the learning activity taxonomy originally developed by Conole et al. (2008), which has subsequently been further fine-tuned and adjusted over time based upon both practical experiences as well as LD research (Toetenel \& Rienties, 2016a, 2016b) (Table 14.1).

Assimilative activities refer to tasks which require student's attention to information. These include watching lecture video, reading the text, listening to an audio 
Table 14.I Learning activity taxonomy

\begin{tabular}{|c|c|c|}
\hline Taxonomy & Type of activity & Example \\
\hline Assimilative & Attending to information & $\begin{array}{l}\text { Read, Watch, Listen, } \\
\text { Think about, Access. }\end{array}$ \\
\hline $\begin{array}{l}\text { Finding and handling } \\
\text { information }\end{array}$ & $\begin{array}{l}\text { Searching for and } \\
\text { processing information }\end{array}$ & $\begin{array}{l}\text { List, Analyse, Collate, } \\
\text { Plot, Find, Discover, } \\
\text { Access, Use, Gather. }\end{array}$ \\
\hline Communication & $\begin{array}{l}\text { Discussing module related } \\
\text { content with at least one } \\
\text { other person (student or } \\
\text { tutor) }\end{array}$ & $\begin{array}{l}\text { Communicate, Debate, } \\
\text { Discuss, Argue, Share, } \\
\text { Report, Collaborate, } \\
\text { Present, Describe. }\end{array}$ \\
\hline Productive & $\begin{array}{l}\text { Actively constructing an } \\
\text { artefact }\end{array}$ & $\begin{array}{l}\text { Create, Build, Make, } \\
\text { Design, Construct, } \\
\text { Contribute, Complete. }\end{array}$ \\
\hline Experiential & $\begin{array}{l}\text { Applying learning in a } \\
\text { real-world setting }\end{array}$ & $\begin{array}{l}\text { Practice, Apply, Mimic, } \\
\text { Experience, Explore, } \\
\text { Investigate. }\end{array}$ \\
\hline Interactive/adaptive & $\begin{array}{l}\text { Applying learning in a } \\
\text { simulated setting }\end{array}$ & $\begin{array}{l}\text { Explore, Experiment, } \\
\text { Trial, Improve, Model, } \\
\text { Simulate. }\end{array}$ \\
\hline Assessment & $\begin{array}{l}\text { All forms of assessment } \\
\text { (summarive, formative } \\
\text { and self assessment) }\end{array}$ & $\begin{array}{l}\text { Write, Present, Report, } \\
\text { Demonstrate, Critique. }\end{array}$ \\
\hline
\end{tabular}

Source: Retrieved from Conole et al. (2008).

file, etc. Finding and handling information activities implies, for example, searching and filtering for relevant literature in a particular topic on the internet. Communication activities refer to a range of practices to communicate such as posting in a discussion forum and replying to peer comments. Productive activities represent the construction of an artefact, such as writing a summary or resolving a problem. Experiential activities provide students with opportunities to apply theories in a real-world setting such as case study, or field trip. Interactive/adaptive activities encourage students to apply what they learned in an experiential environment or interacting with a simulation. Finally, assessment activities evaluate the student's understanding such as writing through the construction of an essay, exam or making a presentation (Conole, 2012; Conole et al., 2008).

For each learning activity, an estimation is made for how long it would take an average student to complete that activity. This estimation is usually determined by the module team and being embedded in the module guide on the VLE as a guidance for students' study time allocation (Figure 14.1). If the time estimation is not explicitly stated in the module guide, it will be determined using agreed conventions for study speed and amount of time allocated to studying figures, tables, images, audio and video within module materials. The time estimation of each learning activity was aggregated at a weekly level (i.e., estimated workload per week). The workload of each module was restricted by its number of credits, with each credit equates one hour of studying. For example, a 30-credit module requires 


\section{Activity 3.3}

(1) Spend approximately 35 minutes on this activity.

The Open University provides guidance on a number of study skills on the StudentHome website. You are encouraged to refer to these guidance notes and excercies as and when it seems useful to you. However, from time to time you will be explicitly directed to one of these OU study skills sessions as part of one of the activities on B100. This is because much of the generic guidance available in the sessions is very relevant to studying $\mathrm{B} 100$ and it would be an unnecesary doubling of effort to recreate very similar guidance here, specificlly for B100. Also, by linking to the generic study skills pages you will get an idea of what else is available there that may be useful to you at some point. This activity on note taking is one of those where you are encouraged to work through a generic study skills session before you return to the B100 website to complete the activity with some B100 specific material.

Figure I4.I Time estimation of learning activity in a module guide.

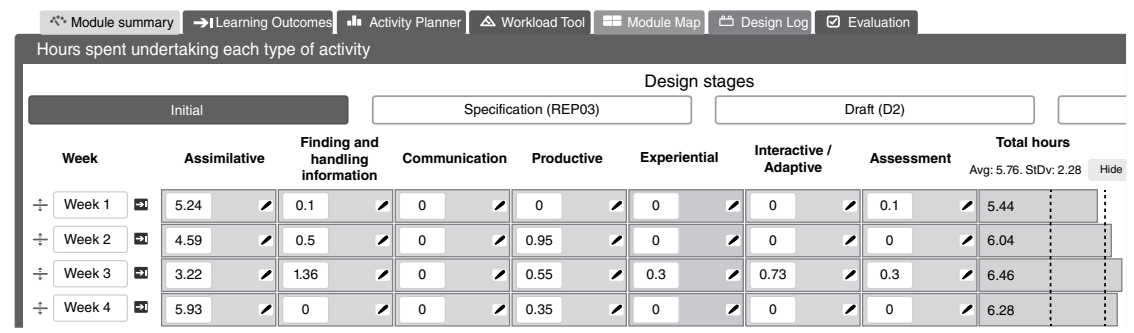

Figure 14.2 Activity planner tool.

300 hours of learning or 8-9 hours per week, and a 60-credit module requires 600 hours of learning or 16-18 hours per week.

When using data to compare module design across disciplines and modules, according to previous work (Rienties \& Toetenel, 2016; Toetenel \& Rienties, 2016a) it is important to classify learning activities in an objective and consistent manner. In particular, each module goes through a mapping process by a module team which consists of an LD specialist, an LD manager, and faculty members. This process typically takes between one to three days for a single module, depending on the number of credits, structure, and quantity of learning resources. First, the learning outcomes specified by the module team were captured by an LD specialist. Each learning activity within the module's weeks, topics, or blocks was categorised under the LD taxonomy and stored in an "activity planner" - a planning and design tool supporting the development, analysis, and sharing of LD (Figure 14.2). Next, the LD team manager reviews the resulting module map before the findings are forwarded to the faculty. This provides academics with an opportunity to comment on the data before the status of the LD is finalised. To sum up, the mapping process is reviewed by at least three people to ensure the reliability and robustness of the data relating to LD. 


\section{4.3 How instructors design online courses}

To understand how instructors designed online courses at the OU, a subset of 37 modules were extracted from the OU Activity Profile tool, which was mapped on a weekly basis. These modules were selected based on the data availability in conjunction with discussion with the LD team, in order to determine a representative sample of the OU courses. Table 14.2 provides descriptive information about the selected modules.

In line with previous findings (Rienties \& Toetenel, 2016; Toetenel \& Rienties, 2016a), assimilative, assessment, and productive activities were the predominant types of learning activity (Table 14.3). Assimilative activities accounted for half of the workload on average $(\mathrm{M}=50.00 \%, \mathrm{SD}=13.03 \%)$, followed by assessment $(\mathrm{M}=24.4 \%, \mathrm{SD}=8.38 \%)$ and productive $(\mathrm{M}=17.60 \%, \mathrm{SD}=12.39 \%)$. There was a large variation in terms of the total workload across modules. All modules have some proportions of assimilative, productive, and assessment but some modules did not have any communication, finding information, interactive, or experiential activities (Table 14.3).

A visual comparison of LDs across the four disciplines suggested that STEM modules were more likely to use experiential and interactive activities than other disciplines (Figure 14.3). Modules in Education, Health, and Languages had the highest proportion of workload for productive activities. A Kruskal-Wallis test indicated that the differences between disciplines in productive $\left(\mathrm{X}^{2}=14.37, p<.01\right)$ and experiential activities $\left(\mathrm{X}^{2}=8.64, p<.05\right)$ were statistically significant. These results based on aggregated figures of LD confirmed findings from previous studies (Rienties \& Toetenel, 2016; Toetenel \& Rienties, 2016a). It also added new insights

Table 14.2 Descriptive statistics of 37 modules

\begin{tabular}{|c|c|c|}
\hline & Frequency & Percent \\
\hline \multicolumn{3}{|l|}{ Credits } \\
\hline $\begin{array}{l}30 \\
60\end{array}$ & 17 & $45.9 \%$ \\
\hline 60 & 20 & $54.1 \%$ \\
\hline \multicolumn{3}{|l|}{ Level } \\
\hline 0 & 3 & $8.1 \%$ \\
\hline 1 & 26 & $70.3 \%$ \\
\hline 2 & 5 & $13.5 \%$ \\
\hline 3 & 3 & $8.1 \%$ \\
\hline \multicolumn{3}{|l|}{ Faculty } \\
\hline Arts \& Social Sciences & 9 & $24.3 \%$ \\
\hline $\begin{array}{l}\text { Business \& Law } \\
\text { Education, Health, }\end{array}$ & 6 & $16.2 \%$ \\
\hline Languages & 9 & $24.3 \%$ \\
\hline STEM & 13 & $35.1 \%$ \\
\hline
\end{tabular}

Note: Level I, 2, 3 at the OU are equivalent to introductory, intermediate, and advanced courses. Level 0 represents access modules. 
Table 14.3 Descriptive statistics of seven types of learning activity in 37 modules

\begin{tabular}{lcrrrr}
\hline & $N$ & Minimum & Maximum & Mean & Std. deviation \\
\hline Assimilative & 37 & $23 \%$ & $75 \%$ & $50.0 \%$ & $13.03 \%$ \\
Information & 37 & $0 \%$ & $8 \%$ & $2.2 \%$ & $1.98 \%$ \\
Communication & 37 & $0 \%$ & $9 \%$ & $2.5 \%$ & $2.96 \%$ \\
Productive & 37 & $2 \%$ & $59 \%$ & $17.6 \%$ & $12.39 \%$ \\
Experiential & 37 & $0 \%$ & $12 \%$ & $1.1 \%$ & $2.25 \%$ \\
Interactive & 37 & $0 \%$ & $19 \%$ & $2.2 \%$ & $4.56 \%$ \\
Assessment & 37 & $13 \%$ & $57 \%$ & $24.4 \%$ & $8.38 \%$ \\
\hline
\end{tabular}

Metric $=\%$ of total workload.

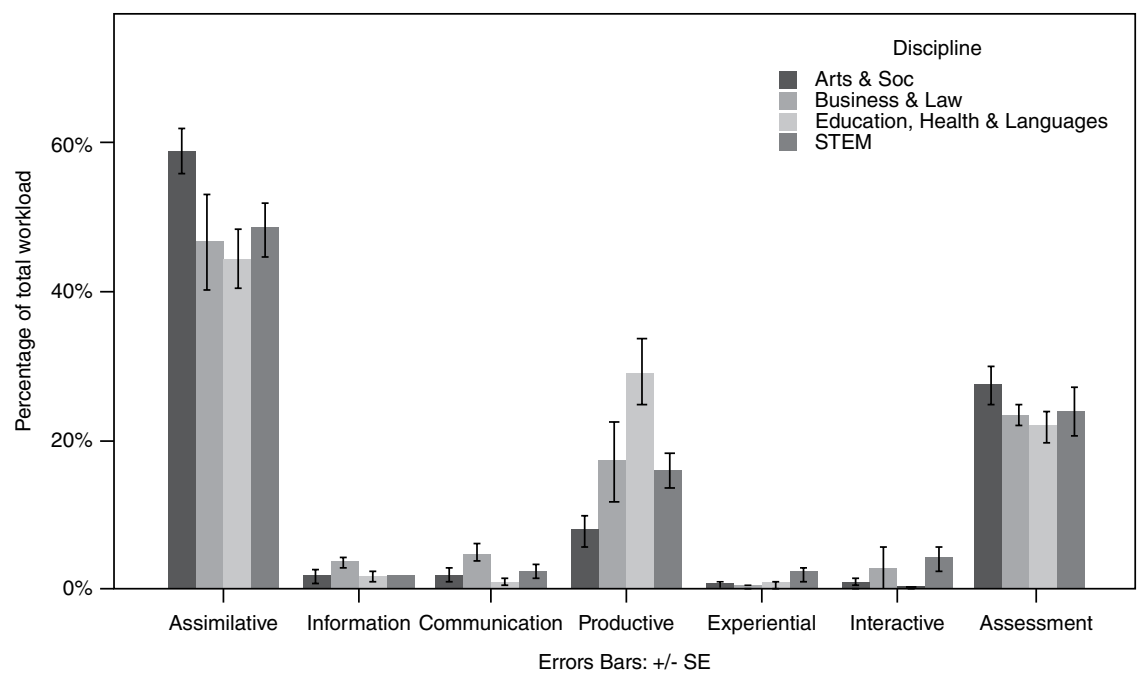

Figure 14.3 A comparison of seven learning activity types across four disciplines.

into the disciplinary differences in LDs. The next section will unpack the changes in LDs over time.

Figure 14.4 visualised the changes in total workload of 37 modules over 31 weeks grouped by the number of credits. By default, the total workload of 30 credit modules was lower than 60 credit modules. However, there were a lot of fluctuations in workload across modules over time $\left(\mathrm{M}_{30 \text { credit }}=6.5, \mathrm{SD}_{30 \text { credit }}=3.11 ; \mathrm{M}_{60 \text { credit }}=8.9\right.$, $\left.\mathrm{SD}_{60 \text { credit }}=4.42\right)$ with a slight decrease in the last 4 weeks toward the end of the module (Table 14.4).

Figure 14.5 illustrates the average time students were expected to spend per module (in hours) on different learning activities over 34 weeks. Each colour 


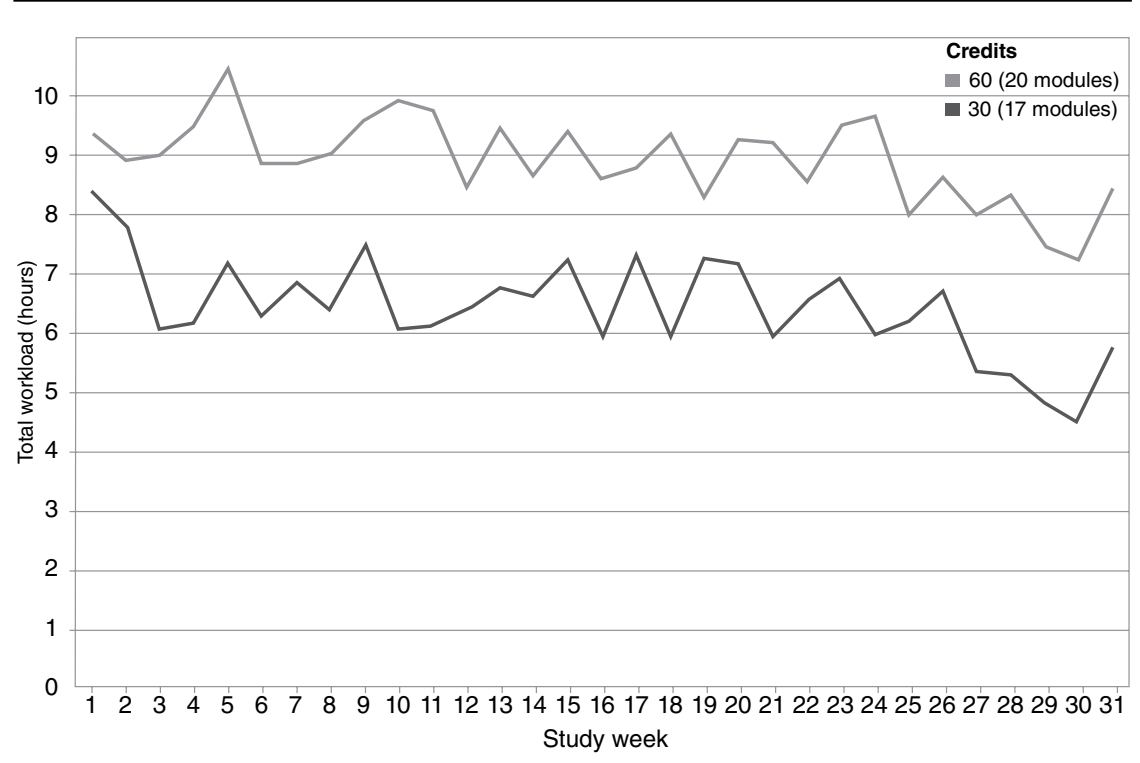

Figure 14.4 Visualisation of total workload over time of 37 modules over 31 weeks.

Table 14.4 Descriptive statistics of seven learning activity types of 37 modules over 3 I weeks

\begin{tabular}{llllll}
\hline & $N$ & Min & Max & Mean & $\begin{array}{l}\text { Std. } \\
\text { deviation }\end{array}$ \\
\hline 30 credits modules & & & & & \\
$\quad$ Assimilative & 475 & 0.0 & 12.4 & 3.1 & 2.36 \\
$\quad$ Information & 475 & 0.0 & 2.3 & 0.1 & 0.31 \\
$\quad$ Communication & 475 & 0.0 & 2.5 & 0.2 & 0.38 \\
Productive & 475 & 0.0 & 9.5 & 1.3 & 1.39 \\
Experiential & 475 & 0.0 & 9.0 & 0.1 & 0.71 \\
Interactive & 475 & 0.0 & 4.4 & 0.2 & 0.78 \\
Assessment & 475 & 0.0 & 10.5 & 1.3 & 2.23 \\
Total & 475 & 0.0 & 23.6 & 6.4 & 3.11 \\
60 credits modules & & & & & \\
Assimilative & 613 & 0.0 & 15.0 & 4.5 & 3.88 \\
Information & 613 & 0.0 & 13.0 & 0.3 & 0.92 \\
Communication & 613 & 0.0 & 11.0 & 0.3 & 0.89 \\
Productive & 613 & 0.0 & 12.5 & 1.3 & 1.94 \\
Experiential & 613 & 0.0 & 1.8 & 0.0 & 0.17 \\
Interactive & 613 & 0.0 & 19.1 & 0.1 & 0.87 \\
Assessment & 613 & 0.0 & 20.0 & 2.4 & 4.06 \\
Total & 613 & 0.0 & 35.9 & 8.9 & 4.42 \\
\hline
\end{tabular}

Metrics $=$ Hours $N=$ Number of data points per module per week. For example, a 30 week long module has 30 data points. 


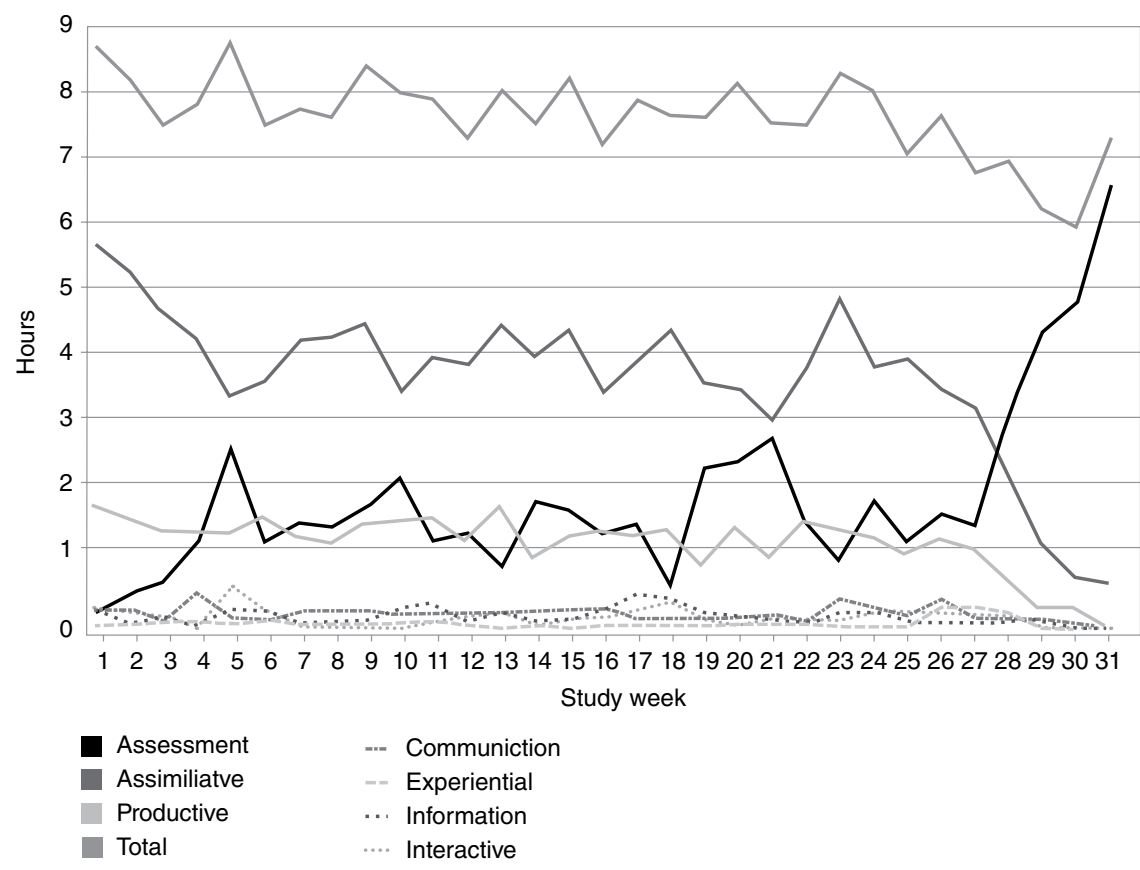

Figure I 4.5 Visualisation of seven learning activity types over time of 37 modules over 3 I weeks.

represents a type of learning activities. The visualisation also confirmed the dominance of assimilative (orange), assessment (blue), and productive (purple) learning activity types. Assimilative activities were present throughout most of the learning process except for the last four weeks and accounted for half of the total workload $(\mathrm{M}=3.90, \mathrm{SD}=3.37)$.

Interestingly, there was an opposite trend between assimilative and assessment activities throughout the course $(\mathrm{r}=-0.462, p<.01)$. More assimilative activities were used at the beginning of a module, whereas more assessments were used toward the end. Assessment activities were also negatively correlated with other types of learning activity (Table 14.5). In other words, teachers deliberately reduced the workload of other learning activity types when an assessment was activated.

After capturing a dynamic picture of LD over time, we took a further step to investigate how LDs were configured across different modules. We reported four exemplary modules across four disciplines with a variety of configurations and patterns of learning activities (Figure 14.6). In line with the findings above, all four modules extensively made use of assimilative (orange), productive (purple), and assessment activities (blue). However, there are subtle differences in the way each module utilised these three activity types.

The first module in Arts followed a "traditional" design, with a lot of reading, watching, listening activities. Its assessment consisted of five continuous assessments, so-called Tutor Marked Assessments (TMAs) every 4-5 weeks and an end 
Table 14.5 Correlation analysis of seven learning activity types over time of 37 modules

\begin{tabular}{|c|c|c|c|c|c|c|c|c|}
\hline & $I$ & 2 & 3 & 4 & 5 & 6 & 7 & 8 \\
\hline $\begin{array}{l}\text { 1. Assimilative } \\
\text { 2. Information } \\
\text { 3. Communication } \\
\text { 4. Productive } \\
\text { 5. Experiential } \\
\text { 6. Interactive } \\
\text { 7. Assessment } \\
\text { 8. Total }\end{array}$ & $\begin{array}{c}1 \\
.082^{* *} \\
.166^{* *} \\
.161^{* *} \\
.021 \\
.016 \\
-.462^{* *} \\
.555^{* *}\end{array}$ & $\begin{array}{c}1 \\
.167^{* *} \\
.167^{* *} \\
-.021 \\
.015 \\
-.115^{* *} \\
.248^{* *}\end{array}$ & $\begin{array}{c}1 \\
.130^{* *} \\
-.022 \\
.050 \\
-.124^{* *} \\
.300^{* *}\end{array}$ & $\begin{array}{c}1 \\
-.002 \\
.008 \\
-.292^{* *} \\
.362^{* *}\end{array}$ & $\begin{array}{c}1 \\
.012^{1} \\
-.062^{*} \\
.078^{* *}\end{array}$ & $\begin{array}{c}1 \\
-.003 \\
.230^{* *}\end{array}$ & $\begin{array}{c}1 \\
.283^{* *}\end{array}$ & I \\
\hline
\end{tabular}

** Correlation is significant at the 0.01 level (2-tailed).

* Correlation is significant at the 0.05 level (2-tailed).

$\mathrm{N}=1088$ data points.

Note: Adapted from Nguyen et al. (2017). 


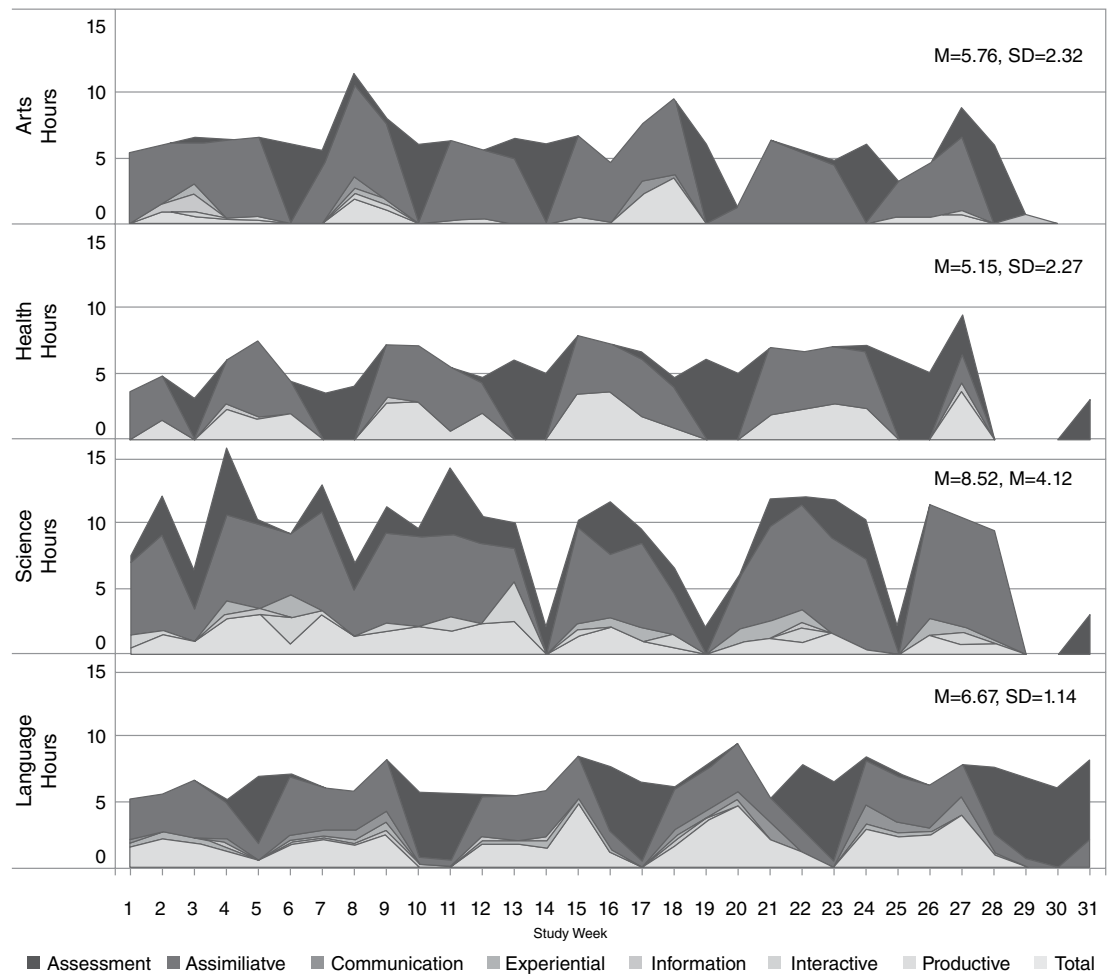

Figure 14.6 Four exemplary modules from Arts, Health, Science, and Languages.

of module assessment (EMA) in week 30. The workload of this module was relatively constant for most parts, except for the peak in week 8 which had a double amount of workload (i.e., 11.31 hours) compared to other weeks.

The second module in Health was similar to the first module in Arts. However, the former used more productive activities and had two-week long studying time for each TMA. The third module in Science adopted a continuous assessment strategy using a lot of quizzes throughout the learning process. This module also had a considerable amount of interactive (yellow) and experiential (light blue) activities compared to other modules. There were several dips in workload in week 14, 19, and 25 which represented TMA preparation weeks. The dip in week 29 represented an EMA preparation week. The fourth module in languages had a higher mix of assimilative and productive activities. There was also a higher presence of communication activities (red) in this module.

In summary, the findings have started to demonstrate through visualisations and statistical analysis the overall trends in LDs across 37 modules over 31 weeks. The three main types of learning activity namely assimilative, productive, and assessment were visible in all modules. There was a moderate negative correlation between 
assimilative and assessment activities. A closer look into each module individually revealed subtle differences in how each teacher utilised each learning activity type.

\subsection{How students engage in online learning activities}

To capture student engagement, the time spent on theVLE (i.e., Moodle) was used as a proxy of student online behavioural engagement. Time spent on the VLE was calculated as the duration between two consecutive clicks, aggregated across all study sections. The data were captured from four weeks before the start of the module until four weeks after the end of the module. Learning activities were planned for over 30 weeks. In order to link LD data with engagement data, the measurements needed to be on the same level of analysis (e.g., weekly). Based on this, behavioural engagement were generated as the average time spent on theVLE per week (in minutes).

Fixed effect models were carried out with the average time spent on VLE per week (Table 14.6) as a dependent variable. For each predictor, four models were applied. First, we ran a normal OLS regression model. Second, a fixed-effect model was used to control for the unobserved heterogeneity of time.Third, we controlled for the fixed effect between modules. Finally, we controlled for the fixed effects of both time and modules. Since assimilative activities account for most of the

Table /4.6 Fixed effect model of VLE engagement per week predicted by learning design activities

\begin{tabular}{|c|c|c|c|c|}
\hline \multirow[t]{2}{*}{$D V=V L E$ per week } & \multicolumn{4}{|c|}{ Unstandardised coefficients } \\
\hline & $(I)$ & (2) & (3) & (4) \\
\hline MODELS & OLS & FE_week & FE_module & FE_module_week \\
\hline Assessment & $\begin{array}{l}\text { 4.98** } \\
(0.57)\end{array}$ & $\begin{array}{l}5.09 * * \\
(0.59)\end{array}$ & $\begin{array}{l}2.47 * * \\
(0.47)\end{array}$ & $\begin{array}{l}2.80 * * \\
(0.47)\end{array}$ \\
\hline Information & $\begin{array}{c}2.40 \\
(2.64)\end{array}$ & $\begin{array}{c}3.23 \\
(2.60)\end{array}$ & $\begin{array}{l}-0.72 \\
(1.98)\end{array}$ & $\begin{array}{l}0.15 \\
(1.94)\end{array}$ \\
\hline Communication & $\begin{array}{l}26.29 * * \\
(2.66)\end{array}$ & $\begin{array}{l}26.29 * * \\
(2.62)\end{array}$ & $\begin{array}{l}16.54^{* *} \\
(2.16)\end{array}$ & $\begin{array}{l}17.44 * * \\
(2.11)\end{array}$ \\
\hline Productive & $\begin{array}{l}1.75 \\
(1.14)\end{array}$ & $\begin{array}{l}1.73 \\
(1.12)\end{array}$ & $\begin{array}{l}-1.84 \\
(1.04)\end{array}$ & $\begin{array}{l}-1.83 \\
(1.03)\end{array}$ \\
\hline Experiential & $\begin{array}{c}3.57 \\
(3.83)\end{array}$ & $\begin{array}{c}4.49 \\
(3.78)\end{array}$ & $\begin{array}{l}-2.07 \\
(2.98)\end{array}$ & $\begin{array}{l}-0.99 \\
(2.91)\end{array}$ \\
\hline Interactive & $\begin{array}{l}11.57 * * \\
(2.23)\end{array}$ & $\begin{array}{l}\text { II.25** } \\
(2.20)\end{array}$ & $\begin{array}{l}-0.33 \\
(1.81)\end{array}$ & $\begin{array}{l}-0.46 \\
(1.78)\end{array}$ \\
\hline Constant & $\begin{array}{l}95.66^{* *} \\
(2.91)\end{array}$ & $\begin{array}{l}95.30^{* * *} \\
(2.85)\end{array}$ & $\begin{array}{r}110.6 * * \\
(2.46)\end{array}$ & $\begin{array}{l}172.1 * * \\
(10.50)\end{array}$ \\
\hline $\begin{array}{l}\text { Observations } \\
\text { Adjusted R-squared }\end{array}$ & $\begin{array}{l}1,088 \\
0.15\end{array}$ & $\begin{array}{l}1,088 \\
0.19\end{array}$ & $\begin{array}{l}1,088 \\
0.55\end{array}$ & $\begin{array}{r}\mathrm{I}, 088 \\
0.58\end{array}$ \\
\hline
\end{tabular}

Standard errors in parentheses. $* p<.05$, ** $p<.01$

Baseline: assimilative.

Source: Adapted from Nguyen et al. (2017). 
workload, they were set as the baseline. Therefore, the following results should be interpreted relative to assimilative activities.

Table 14.6 shows that assessment activities were positively and significantly related to the average time spent in the VLE per week in all four models (Nguyen et al., 2017). In Models 1 and 2, the effect of assessment activities was almost the same $(B=4.98, \mathrm{SE}=0.57, p<.01$ and $B=5.09, \mathrm{SE}=0.59, p<.01$, respectively). The effect of assessment activities became smaller in Model 3 and Model 4 when differences between modules were taken into account. On average, an additional hour allocated for assessment activities was associated with $2.47(\mathrm{SE}=0.47, p<.01)$ and $2.80(\mathrm{SE}=0.47, p<.01)$ minutes increase in the average time spent on theVLE per week in Model 3 and Model 4, respectively.

Communication activities were also positively associated with the time spent on VLE per week in all four models. For every hour increase in communication activities, the time spent on VLE per week increased by 17.44 minutes (SE $=2.11$, $p<.01)$. The effect of communication activities was the strongest amongst all other learning activity types. Interactive activities were positively correlated with time spent on VLE in Model 1 and Model 2. However, the effect of interactive activities became non-significant when the differences between modules were taken into account (Model 3 \& Model 4).

Overall, LD activities explained up to $58 \%$ of the variability in student engagement in the VLE per week when controlling for the heterogeneity between modules. To further explore the relationship between LD and student engagement. We visualised two exemplary modules in Arts and in Languages (Figure 14.7). These two modules had a relatively similar design but the level of VLE engagement seemed to be very different. In the Arts module, we can see a peak in VLE activity

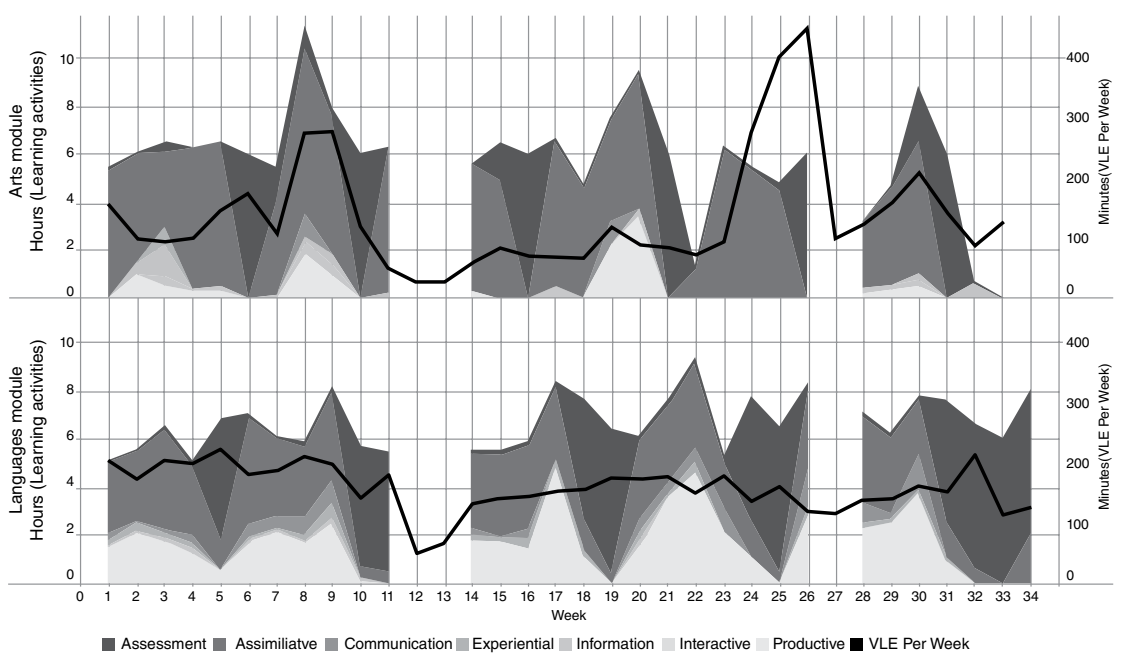

Figure 14.7 Learning design and VLE activity of two modules in Arts and Languages. 
in week 8-9 due to the increase in workload. The level of engagement then decreased during the Christmas breaks and sharply increase just before the Easter break in week 26. In contrast, the level of engagement in the Language module was relatively constant throughout the module, with the exception during Christmas breaks. The level of engagement in both module slightly increased in assessment weeks, which confirmed the findings from the fixed-effect models.

\section{4.5 Study patterns and academic performance}

When teachers design for learning, they often estimate the workload of each activity and the corresponding time period for each activity (e.g., take 3 hours to read chapter 2 in week 2). LD is often embedded in the course syllabus and acts as a guideline for students to self-regulate their learning process (Biggs \& Tang, 2007). However, students as agents consciously and perhaps opportunistically make decisions on what, how, and when to engage in a particular range of learning activities (Winne, 2017). While teachers might think that a student will read say chapter 2 in week 2 , perhaps some students are already pre-reading materials from week 4, while other students may not have watched the introduction video of week 1.Therefore, by having a better understanding of how much time students spent on respective learning materials and when in time they studied these learning materials, this may enhance our intertemporal understanding of how students make complex study decisions.

Nguyen et al. (2018b) investigated how students study patterns compare to the initial study regime produced for the LD, together with how different groups of performance and LD were related to these study patterns. The analyses were conducted using trace data from the VLE longitudinally over 28 weeks, with 387 participating students, and replicated over two semesters in 2015 and 2016. Two types of study patterns were computed which capture how much time a student spent on studying a particular study material:

- $\quad$ in advance - material $\mathrm{x}$ assigned to week $\mathrm{t}$ was studied during or before week $\mathrm{t}$

- catching up or revise - material $\mathrm{x}$ assigned to week $\mathrm{t}$ was studied after week $\mathrm{t}$

Overall, given the same study materials, the passed and the excellent group of students spent more time on studying in advance and catch up than the students who failed in both semesters (Figures 14.8 \& 14.9). In Fall 2015, passed and excellent students spent on average each week 1.81 hours $(\mathrm{SD}=3.43)$, and 2.3 hours $(\mathrm{SD}=$ 3.52) on studying in advance, compared to students who failed with an average of 0.22 hours $(\mathrm{SD}=1.05)$. Similar trends in the time studying in advance across the three groups were also presented in Fall 2016. In Fall 2015, passed and excellent students followed a similar pattern studying in advance. However, in Fall 2016 passed and students who failed portrayed a similar pattern for all study materials from week 1 to week 12. From week 13 onwards, passed students spent more time studying in advance than students who failed. A lot of time was spent on studying in advance in weeks 8, 18, and 27 (for Fall 2015) because of the respective assessments (TMAs) in these weeks (Figure 14.8). 


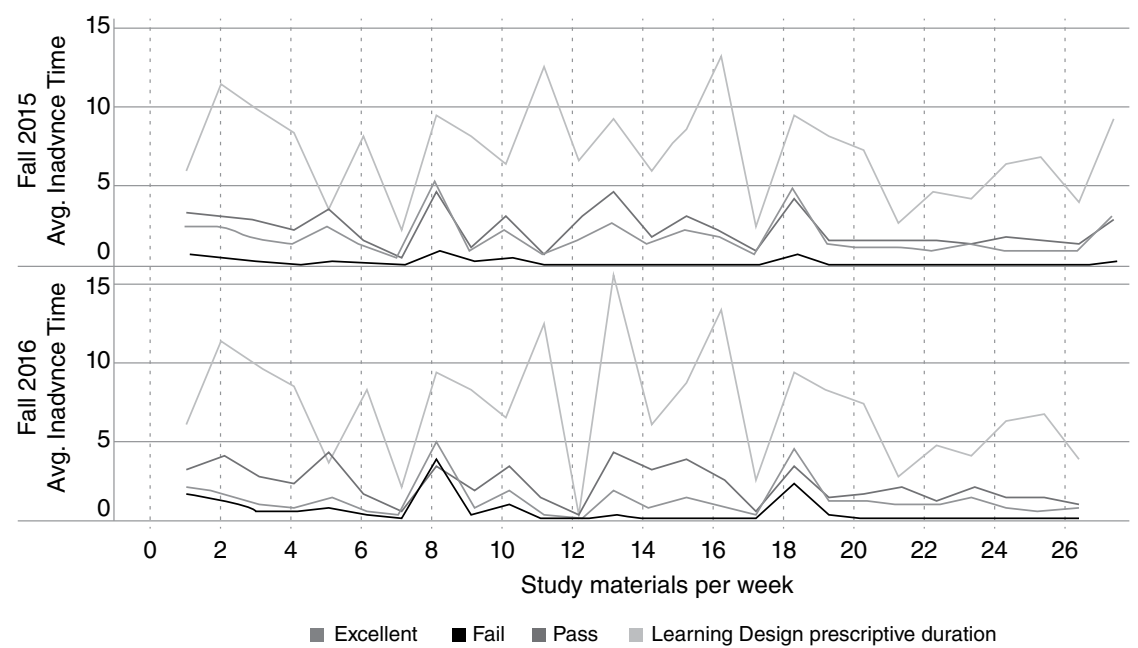

Figure I 4.8 Number of hours spent on studying in advance.

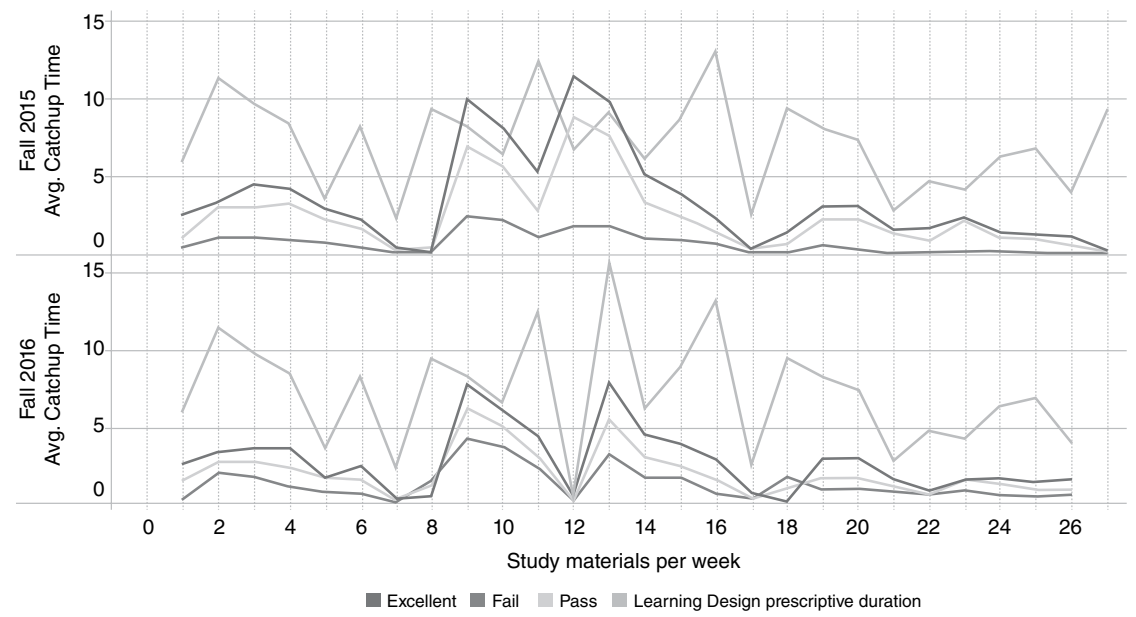

Figure 14.9 Number of hours spent on studying catching up and revising.

Two study materials in weeks $9-10$ (block 2.1) and weeks 12-13 (block 2.3) represented red-flags of overwhelming workloads since they were associated with an increase in both studying in advance and catch up time (Figures 14.8 and 14.9). In Fall 2015, passed and excellent students spent much more time to catch up on both of the materials, while the gap was smaller in 2016.

While students who passed consistently spent more time studying both in advance and catch up than students who failed, the relative frequencies revealed a different picture. In both semesters, all three groups of students spent a similar 


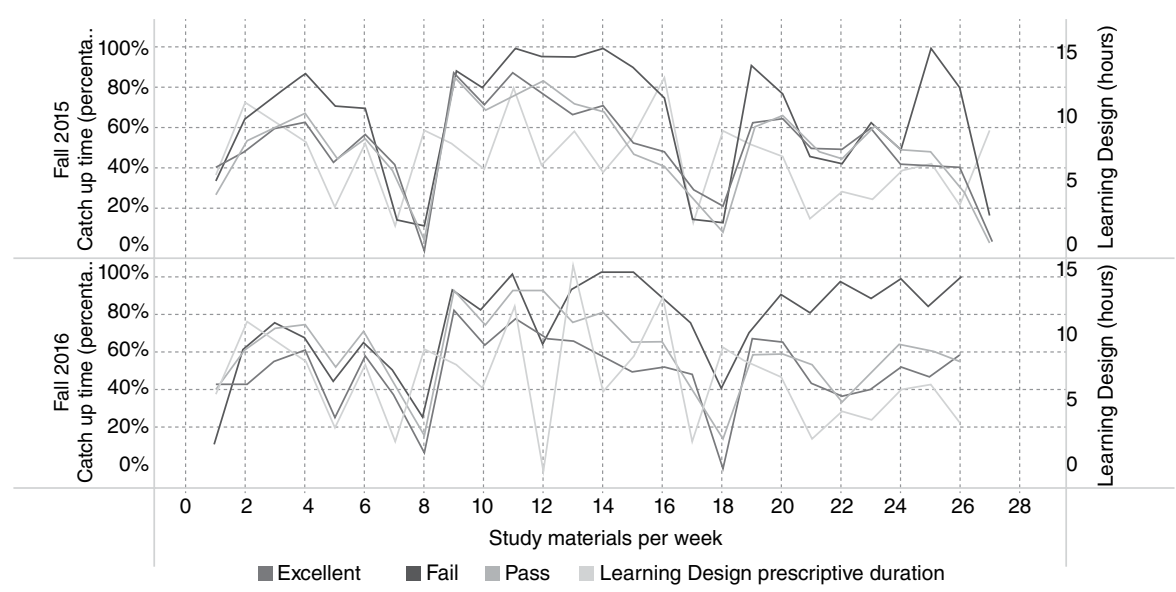

Figure 14.10 Percentage of time spent on studying catching up.

percentage of their time studying in advance in weeks which had a TMA (week 8, 18, 27). However, in Fall 2015 students who failed spent a higher proportion of their time on catching up activities (61\% on average) than passed $(56 \%)$ and excellent students (55\%) in almost all weeks (Figure 14.10).

In Fall 2016, the three groups shared a similar percentage of study time on catching up from week 1 to week 12. After week 12, students who failed spent on average much higher proportion of their time on catching up activities compared to passed and excellent students. Towards the end of the course, the gap between failed and passed/excellent students increased considerably (Figure 14.10).

In other words, the initial visualisations indicated that student engagement on VLE was lower than the suggested time spent in LD. High-performing students, who achieved a pass or excellent grade shared similar patterns of engagement. However, low-performing students spent the least amount of time on VLE and the highest proportion of their studying time on catching up and revising activities.

By having a better understanding of how, when students study on which materials, and how these behavioural patterns connected to LD, teachers may be in a much better position to reflect and adjust their teaching practices. By explicitly pointing out which study materials were under or over-used, teachers can act on these materials. This information can be fed back into an LA dashboard, which would support teachers and learning designers to track how the students progressed through each individual study material (on-track or lagging behind). Teachers can use this information to adjust the study workload and re-arrange the structure of learning activities accordingly.

\section{4.6 Discussion and moving forwards}

The increasing development in online and distance education has provided researchers with an unprecedented amount of data generated by both students and 
educators (Shum, 2012). By utilising digital traces of students' activities combined with information about the course design, Chapter 14 unpacked some of the temporal characteristics of how teachers design for learning and how LD influences student engagement in distance education. Findings from Chapter 14 showed that assimilative activities, such as reading, watching, and listening, were predominantly used at the beginning and throughout the module. Assimilative activities were often accompanied by productive activities which required students to reflect on the information they assimilated. Furthermore, the study workload varied from modules to modules and fluctuated considerably from weeks to weeks.

These findings highlighted a mismatch between educational literature, institutional policies, and the actual LDs. Previous research suggested that a balanced and consistent study workload is essential to student success (Bowyer, 2012; Whitelock et al., 2015). However, in practice the study workload is difficult to estimate due to the quantity and variety of learning activities used by teachers. The effect of inconsistent workload could be even more detrimental to OU students because the majority of them are engaged in either a full-time or part-time employment in parallel to studying. By visualising LD on a week by week basis, teachers can reflect on the (im)balance of workload in their module and improve their LDs.

Chapter 14 showed that LD plays an important role in LA research by not only improving its model accuracy by taking into account the contextual heterogeneity across modules but also offering concrete and actionable feedback to teachers. The level of engagement on VLE by students was lower than the expected workload by teachers in most weeks throughout the course timeline. What is more important was LA models informed by LD can help teachers to identify problematic learning activities in which students spent an excessive amount of time revisiting or when did students start to fall behind the course timeline. We need to go beyond this kind of simple prediction, although it is accurate, to ask real important questions, such as which concept or learning activity student $\mathrm{X}$ was struggling with, and since when student X started falling behind on these activities. Other specific questions about the LD could be asked, such as whether students engaged in material X, how long students spent on learning activity $\mathrm{Y}$, and how often students revisited concept Z. The type of fine-grained analysis illustrated in this thesis allows researchers to ask and answer some of these meaningful questions.

However, there are a lot unknown about the changes in LD practices and student engagement over a longer period of time, such as semesters or years. Therefore, future research should consider extending the longitudinal design, such as examining the changes in LD of the same module over different semesters, the changes in engagement pattern of the same student as they progressed through different LDs, and the changes of LD in the same discipline/qualification.

Furthermore there is a lack of studies on how LD-informed LA could be beneficial to students learning progress. For example, recommendation systems could be built based on patterns of engagement of the previous cohort of students to support the subsequent cohorts. Students could use insights from the previous cohort to plan and self-regulate their own learning process such as how much time should they expect to spend on certain learning activities, which concept that 
students from previous years struggled with, and how high-performing students engaged throughout the course.

\subsection{Implications for practice}

Chapter 14 has shown that while student engagement was largely driven by LD, there are many potential misalignments between what teachers think students do and what they actually do. By having a "reality check" based on actual student behaviour, teachers can identify potential problems in their LD and make appropriate adjustments. It is important to have frequent check-ins with students not only on the assignment deadline but throughout their learning process. It might be too late to intervene by the time a student appears as "at-risk" on the LA system. LA should go beyond simple click count with more fine-grained metrics such as the duration student spent on each learning activity and whether students are ontrack or falling behind. This type of fine-grained analysis tightly linked to LD could provide important new insights to teachers and may help them to effectively intervene where necessary.

\section{References}

Agostinho, S., Bennett, S., Lockyer, L., \& Harper, B. (2011). The future of learning design. Learning, Media and Technology, 36(2), 97-99.

Biggs, J. B., \& Tang, C. (2007). Teaching for quality learning at university (3rd ed.). Maidenhead: Open University Press.

Bowyer, K. (2012). A model of student workload. Journal of Higher Education Policy and Management, 34(3), 239-258.

Clow, D. (2013). An overview of learning analytics. Teaching in Higher Education, 18(6), 683-695.

Conole, G. (2012). Designing for learning in an open world (Vol. 4). Heidelberg: Springer Science \& Business Media.

Conole, G., Brasher, A., Cross, S., Weller, M., Clark, P., \& Culver, J. (2008).Visualising learning design to foster and support good practice and creativity. Educational Media International, 45(3), 177-194.

Cross, S., Galley, R., Brasher, A., \& Weller, M. (2012). Final project report of the OULDI-JISC Project: challenge and change in curriculum design process, communities, visualisation and practice. York: JISC. Retrieved from http://www.open.ac.uk/blogs/OULDI/wp-content/ uploads/2010/11/OULDI_Final_Report_Final.pdf

Dalziel, J., Conole, G., Wills, S., Walker, S., Bennett, S., Dobozy, E., ... Bower, M. (2016). The Larnaca declaration on learning design. Journal of Interactive Media in Education, 2016(1), $1-24$.

Ferguson, R. (2012). Learning analytics: drivers, developments and challenges. International Journal of Technology Enhanced Learning, 4(5-6), 304-317.

Gašević, D., Dawson, S., Rogers, T., \& Gasevic, D. (2016). Learning analytics should not promote one size fits all: the effects of instructional conditions in predicting academic success. The Internet and Higher Education, 28, 68-84.

Herodotou, C., Rienties, B.,Verdin, B., \& Boroowa, A. (2019). Predictive learning analytics' at scale': guidelines to successful implementation in higher education. Journal of Learning Analytics, 6(1), 85-95. 
Hillaire, G., Rienties, B., Fenton-O'Creevy, M., Zdrahal, Z., \& Tempelaar, D. (2022). Incorporating student opinion into opinion mining: A student sourced sentiment analysis classifier. In B. Rienties, R. Hampel, E. Scanlon, \& D. Whitelock (Eds.), Open world learning: research, innovation and the challenges of high-quality education (pp. 171-186). London: Routledge.

Kuzilek, J., Hlosta, M., Herrmannova, D., Zdrahal, Z., \& Wolff, A. (2015). OU Analyse: analysing at-risk students at The Open University. Learning Analytics Review, 1-16.

Laurillard, D., Kennedy, E., Charlton, P., Wild, J., \& Dimakopoulos, D. (2018). Using technology to develop teachers as designers of TEL: evaluating the learning designer. British Journal of Educational Technology, 49(6), 1044-1058.

Lockyer, L., \& Dawson, S. (2011). Learning designs and learning analytics. In the proceedings of the 1st international conference on learning analytics and knowledge, 153-156.

Nguyen, Q., Huptych, M., \& Rienties, B. (2018a). Linking students' timing of engagement to learning design and academic performance. In the proceedings of the 8th International Learning Analytics \& Knowledge Conference, Sydney, Australia, 141-150.

Nguyen, Q., Huptych, M., \& Rienties, B. (2018b). Using temporal analytics to detect inconsistencies between learning design and student behaviours. Journal of Learning Analytics, 5(3), 120-135.

Nguyen, Q., Rienties, B., \& Toetenel, L. (2017a). Mixing and matching learning design and learning analytics. In the proceedings of the Learning and Collaboration Technologies: Forth International Conference, LCT 2017, Part II, Held as Part of HCI International 2017, Cham, 302-316.

Nguyen, Q., Rienties, B., \& Toetenel, L. (2017b). Unravelling the dynamics of instructional practice: a longitudinal study on learning design andVLE activities. In the proceedings of the 7th International Learning Analytics \& Knowledge Conference, Vancouver, British Columbia, Canada, 168-177.

Nguyen, Q., Rienties, B., Toetenel, L., Ferguson, R., \& Whitelock, D. (2017). Examining the designs of computer-based assessment and its impact on student engagement, satisfaction, and pass rates. Computers in Human Behavior, 76, 703-714.

Nguyen, Q., Thorne, S., \& Rienties, B. (2018). How do students engage with computerbased assessments: impact of study breaks on intertemporal engagement and pass rates. Behaviormetrika, 45(2), 597-614.

Rienties, B., Tempelaar, D., Nguyen, Q., \& Littlejohn,A. (2019). Unpacking the intertemporal impact of self-regulation in a blended mathematics environment. Computers in Human Behavior, 100, 345-357.

Rienties, B., \& Toetenel, L. (2016). The impact of learning design on student behaviour, satisfaction and performance: A cross-institutional comparison across 151 modules. Computers in Human Behavior, 60, 333-341.

Rizvi, S., Rienties, B., Kizilcec, R., \& Rogaten, J. (2022). Culturally adaptive learning design: a mixed-method study of cross-cultural learning design preferences in MOOCs. In B. Rienties, R. Hampel, E. Scanlon, \& D. Whitelock (Eds.), Open world learning: research, innovation and the challenges of high-quality education (pp. 103-116). London: Routledge.

Shum, S. B. (2012). Learning analytics policy brief. UNESCO Institute for Information Technology in Education.

Tempelaar, D., Rienties, B., Mittelmeier, J., \& Nguyen, Q. (2018). Student profiling in a dispositional learning analytics application using formative assessment. Computers in Human Behavior, 78, 408-420. 
Toetenel, L., \& Rienties, B. (2016a). Analysing 157 learning designs using learning analytic approaches as a means to evaluate the impact of pedagogical decision making. British Journal of Educational Technology, 47(5), 981-992.

Toetenel, L., \& Rienties, B. (2016b). Learning design-creative design to visualise learning activities. Open Learning: The Journal of Open, Distance and e-learning, 31(3), 233-244.

Ullmann,T. D. (2019). Automated analysis of reflection in writing: validating machine learning approaches. International Journal of Artificial Intelligence in Education, 29(2), 217-257.

Whitelock, D., Thorpe, M., \& Galley, R. (2015). Student workload: a case study of its significance, evaluation and management at the Open University. Distance Education, 36(2), 161-176.

Winne, P. H. (2017). Learning analytics for self-regulated learning. In C. Lang, G. Siemens, A. F. Wise, \& D. Gaševic (Eds.), The handbook of learning analytics (1st ed., pp. 241-249). Alberta, Canada: Society for Learning Analytics Research (SoLAR).

Wise, A. F., Cui, Y., Jin, W., \& Vytasek, J. (2017). Mining for gold: identifying content-related MOOC discussion threads across domains through linguistic modeling. The Internet and Higher Education, 32, 11-28. 